\title{
Mössbauer and Raman spectroscopic characterization of iron and carbon in iron-loaded Japanese cypress charcoal
}

\author{
Takayuki Yamagishi ${ }^{1}$, Shigeru Yamauchi ${ }^{2}$, Kyoko Suzuki ${ }^{3}$, Tsutomu Suzuki ${ }^{3}$, Yasuji Kurimoto ${ }^{2}$, \\ Tsutomu Takayama ${ }^{4}$ and Yoichi Sakai ${ }^{4}$
}

\begin{abstract}
Japanese cypress (Chamaecyparis obtusa) wood powder impregnated with $\mathrm{Fe}^{3+}$ ions was carbonized using one-step and two-step procedures, and the iron-loaded charcoal was examined using Mössbauer and Raman spectroscopy to elucidate the physicochemical states of iron and carbon after carbonization at various temperatures. In the one-step procedure, the Mössbauer spectra confirmed that charcoal carbonized at $750^{\circ} \mathrm{C}$ and $800^{\circ} \mathrm{C}$ contained $\mathrm{Fe}_{3} \mathrm{C}$, suggesting that the reduction of $\mathrm{Fe}^{3+}$ started at lower than $750^{\circ} \mathrm{C}$. The content of $\mathrm{Fe}_{3} \mathrm{C}$ increased substantially in charcoal carbonized at $850^{\circ} \mathrm{C}$ and $900^{\circ} \mathrm{C}$, and metallic iron ( $\gamma$-Fe and/or $\alpha$-Fe) was also detected in these charcoal samples. Raman spectral line-shapes of the charcoal carbonized at $750^{\circ} \mathrm{C}$ and $800^{\circ} \mathrm{C}$ were notably different from those of charcoal carbonized at $850^{\circ} \mathrm{C}$ and $900^{\circ} \mathrm{C}$, which indicated that crystallization of carbon progressed rapidly in the temperature range $800-850^{\circ} \mathrm{C}$. The changes in Raman spectra probably corresponded to those in the Mössbauer spectra, namely, the graphitization was closely related to the reduction of $\mathrm{Fe}^{3+}$. The degree of graphitization in the charcoal carbonized at $850^{\circ} \mathrm{C}$ using the two-step procedure was higher than that using the one-step procedure. Mössbauer spectra suggested that the two-step carbonization enhances the yield of ferromagnetic iron species in iron-loaded charcoal.
\end{abstract}

Keywords: Iron-loaded charcoal, Mössbauer spectroscopy, Raman spectroscopy, Metallic iron, $\mathrm{Fe}_{3} \mathrm{C}$

\section{Introduction}

Carbon forms various allotropes that exhibit valuable characteristics, which has led to a wealth of studies of these allotropes to create new functional materials in a wide range of scientific fields. The number of reports on functional carbon materials has increased dramatically since nanocarbons, fullerene, graphene, and carbon nanotubes, have been developed. Functional carbon materials exhibit excellent electrical conductivity, thereby providing added value. Furthermore, carbon, which is an inexpensive conductive filler, can be produced on a large scale.

\footnotetext{
*Correspondence: sigeru@iwt.akita-pu.ac.jp

${ }^{2}$ Institute of Wood Technology, Akita Prefectural University, 11-1

Kaieisaka, Noshiro 016-0876, Japan

Full list of author information is available at the end of the article
}

In the last two decades, woody biomass has drawn public attention as a sustainable energy source. Although the biomass is considered as an important source of carbon, its practical uses have been hindered by its disadvantages. The carbon content of wood is much lower than that of fossil fuels (petroleum, coal, etc.), and the biomass can be difficult to handle, because of its extremely limited solubility in any solvents.

T. Suzuki and K. Suzuki have studied the carbonization and gasification of wood to enlarge the versatility of woody biomass, revealing that the formation of crystallized mesoporous carbon with high electrical conductivity is accelerated at relatively low temperatures by coexisting iron or nickel salts in the carbonization procedures [1-8]. They claimed that such a high electrical quality of the crystalized carbon should be related to a novel carbon structure, "graphite-shell-chains"
Springer Open (c) The Author(s) 2020. This article is licensed under a Creative Commons Attribution 4.0 International License, which permits use, sharing, adaptation, distribution and reproduction in any medium or format, as long as you give appropriate credit to the original author(s) and the source, provide a link to the Creative Commons licence, and indicate if changes were made. The images or other third party material in this article are included in the article's Creative Commons licence, unless indicated otherwise in a credit line to the material. If material is not included in the article's Creative Commons licence and your intended use is not permitted by statutory regulation or exceeds the permitted use, you will need to obtain permission directly from the copyright holder. To view a copy of this licence, visit http://creativeco mmons.org/licenses/by/4.0/. 
[9], induced by chemical reactions with metal-salt species. Moreover, Suzuki and Suzuki have promoted the practical application of the crystallized charcoal made from iron-loaded wood using a two-step carbonization method $[5,8]$, because iron salts can generally be purchased much inexpensively compared with nickel salts. In addition, iron-loaded charcoal possesses a potential to be utilized as carbon-based magnetic materials. Two-step carbonization is ordinarily used to synthesize activated charcoal. The first step is heat-treatment at relatively low temperatures to remove tar and pyroligneous acids, and then the second step is real carbonization at higher temperatures to obtain the desired charcoal.

The chemical roles of metal salts are, however, still controversial as to the electrical properties and formation mechanism of the nanoshells. A deeper understanding of changes in the chemical state of metals is important to elucidate the whole carbonization mechanism; however, there have been few studies focusing on the chemical changes of metal during the carbonization processes. Mössbauer spectroscopy is a powerful tool to determine the electron states of iron in solid: valences, spin states, internal magnetic fields, etc. Nevertheless, there have been no Mössbauer studies on iron-loaded charcoal, and therefore, it is expected that new findings of the physicochemical state of iron will be obtained from Mössbauer characterization. Raman spectroscopy is recognized to provide important information about graphite and graphite-like structures. Recently, the detection of $\mathrm{G}^{\prime}(2 \mathrm{D})$-band due to $s p^{2}$-carbon has been frequently adopted as a criterion of graphitization in the carbonmaterial sector. To obtain clues as to mechanisms of carbonization, it seems useful to investigate a dependence of products on the reaction process.

The aim of the present study is to understand the physicochemical changes of iron and carbon during carbonization. The characterization of iron and carbon in iron-loaded charcoal carbonized at various temperatures was performed using Mössbauer and Raman spectroscopy. Here, the one-step carbonization procedure was adapted in addition to the two-step one which Suzuki and Suzuki developed [8].

\section{Experimental}

\section{Preparation of wood powder impregnated with iron(III)} nitrate

Wood powder with $\mathrm{Fe}^{3+}$ ions was prepared essentially in accordance with the previous work [8]. Japanese cypress (Chamaecyparis obtusa) wood powder, which passed through a mesh opening of $1.4 \mathrm{~mm}$ but not through a mesh opening of $0.5 \mathrm{~mm}$, was used as the starting material for the production of iron-loaded charcoal. The raw wood powder was impregnated with $\mathrm{Fe}^{3+}$ ions as aqueous
iron(III) nitrate solution with a concentration of $3 \mathrm{wt} \%$ of an iron amount. Excess solvent water was removed using a rotary evaporator at about $60{ }^{\circ} \mathrm{C}$ under reduced pressure, and subsequently, the wood powder containing $\mathrm{Fe}^{3+}$ ions was dried under vacuum using an oil rotary pump at ambient temperature.

\section{Carbonization of iron-impregnated wood powder}

The schematic of the carbonization apparatus used in this study has been described in detail previously [2]. Two kinds of carbonization procedure were adopted in this study. The first procedure was one-step carbonization. Vacuum-dried wood powder $(50 \mathrm{~g})$ was added into a stainless-steel vessel, and the vessel was placed in a vertical stainless-steel tube reactor. The reactor was heated to a carbonization temperature $\left(\mathrm{CT} ; 750{ }^{\circ} \mathrm{C}, 800{ }^{\circ} \mathrm{C}\right.$, $850{ }^{\circ} \mathrm{C}$, or $\left.900{ }^{\circ} \mathrm{C}\right)$ in a downstream of $\mathrm{N}_{2}$ gas $(1 \mathrm{~mL}$ STP $\mathrm{cm}^{-2} \mathrm{~min}^{-1}$ ) using an electric furnace; the temperature was increased at a rate of $10{ }^{\circ} \mathrm{C} / \mathrm{min}$. The reactor was maintained at the desired temperature for $1.0 \mathrm{~h}$, and it was cooled down rapidly to room temperature by removal from the furnace and blowing air over it. All carbonization processes, including the cooling process, were carried out under $\mathrm{N}_{2}$ gas flow.

The second procedure was two-step carbonization. Charcoal carbonized at $500{ }^{\circ} \mathrm{C}$ by the one-step procedure was used as the starting material and re-carbonized at $850{ }^{\circ} \mathrm{C}$ using the one-step carbonization method described above.

The iron-loaded charcoal samples carbonized at $750{ }^{\circ} \mathrm{C}$, $800{ }^{\circ} \mathrm{C}, 850{ }^{\circ} \mathrm{C}$, and $900{ }^{\circ} \mathrm{C}$ using the one-step method are denoted as Fe-C750-1, Fe-C800-1, Fe-C850-1, and $\mathrm{Fe}-\mathrm{C} 900-1$, respectively, and the charcoal sample produced at $850{ }^{\circ} \mathrm{C}$ using the two-step method is abbreviated as Fe-C850-2.

\section{Raman spectroscopy}

Raman spectra were obtained using a Raman spectrometer (inVia Raman Microscope, Renishaw PLC, UK) with $532 \mathrm{~nm}$ laser excitation (0.75 or $1.5 \mathrm{~mW}$ ). Backscattered Raman signals were collected through a microscope $(50 \times$ objective lens) with a spectral resolution of approximately $3 \mathrm{~cm}^{-1}$, and the exposure time was $50 \mathrm{~s}$. Raman measurements were repeated at more than 30 different points for each charcoal sample because the measurement scope $(\sim 2 \mu \mathrm{m}$ diameter $)$ was too small for a sample size, in which one measurement might lead to a possible incorrect result for a sample with inhomogeneity. The calibration of Raman shifts was carried out using the 520 and $1332 \mathrm{~cm}^{-1}$ for a silicon wafer and diamond, respectively. 


\section{Mössbauer spectroscopy}

${ }^{57} \mathrm{Fe}$ Mössbauer spectra were obtained in a conventional transmission mode on a Mössbauer spectrometer (Model-222, Topologic System Co.) with a ${ }^{57}$ Co (Rh) source $(925 \mathrm{MBq})$. All measurements were carried out at $298 \mathrm{~K}$. The Mössbauer spectra were analyzed using a curve-fitting processing with the MossWinn 4.0Pre. Program, assuming that all the spectra were composed of Lorentzian-shaped peaks. The isomer shift (IS) and Doppler velocity scale were calibrated with respect to the sextet of $\alpha$-Fe at room temperature. The sample thicknesses of the iron-loaded charcoal samples ranged from 21 to $24 \mathrm{mg} / \mathrm{cm}^{2}$.

\section{Results and discussion}

\section{Raman spectroscopy}

Figure 1 shows a typical Raman spectra of the ironloaded charcoal samples. Although there were not found significantly different spectral-shapes among the 30 measurement points for Fe-C750-1, Fe-C800-1 and $\mathrm{Fe}-\mathrm{C} 850-2$, it was proved that the spectra showed a measurement-point dependence for Fe-C850-1 and Fe-C900-1 due to the sample inhomogeneity. The different Raman spectral-shapes due to the inhomogeneity are illustrated for Fe-C850-1 in Fig. 2, where a, b, and c set

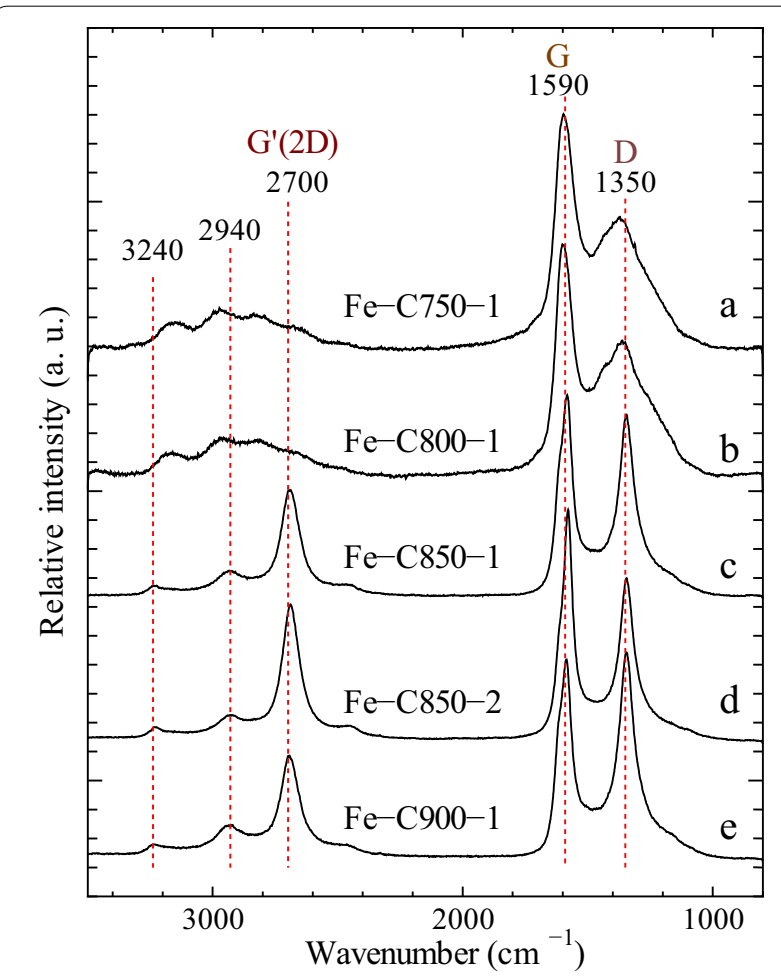

Fig. 1 Typical Raman spectra of iron-loaded charcoal samples: a Fe-C750-1; b Fe-C800-1; c Fe-850-1; d Fe-C850-2; e Fe-C900-1 for the three different points. These results are described in details in the preceding paragraph. The whole lineshape of the Raman spectrum changes remarkably as CT increases from $800{ }^{\circ} \mathrm{C}$ to $850{ }^{\circ} \mathrm{C}$, as shown in Fig. 1 . The drastic spectral changes are caused by the sharpening of the D-band and the appearance of the $\mathrm{G}^{\prime}$-band, indicating crystallization of carbon (i.e., graphitization).

As is well known, D-, G-, and G'-bands are due to $s p^{2}$ carbon. Unlike G-band, D- and G'-bands are not ordinary Raman bands and their shifts are dependent on the wavelength of an excitation laser. Furthermore, the intensity of $G^{\prime}$-band is not proportional to that of D-band, despite the fact that $\mathrm{G}^{\prime}$-band is the overtone of D-band. Nearly perfect graphite that has few lattice defects shows a strong G'-band but an extremely weak or no D-band. Additionally, D-band intensity increases as a lattice defect increases [10]. Accordingly, the CT-dependence of the D-band line-shape and G'-band intensity suggest that graphitization progresses substantially between $800{ }^{\circ} \mathrm{C}$ and $8500^{\circ} \mathrm{C}$.

Figure 2 demonstrates three Raman spectra for different three positions on the Fe-C850-1 sample showing different $G^{\prime}$-band intensities and D-band line-shapes. The top spectrum exhibits no $G^{\prime}$-band and a collapsed D-band as well as those of Fe-C750-1 and Fe-C8001. Such spectra were obtained for approximately $15 \%$ of all the measurements points of $\mathrm{Fe}-\mathrm{C} 850-1$ in this study. This is an important result, which indicates that $\mathrm{Fe}-\mathrm{C} 850-1$ contains a certain amount of amorphous

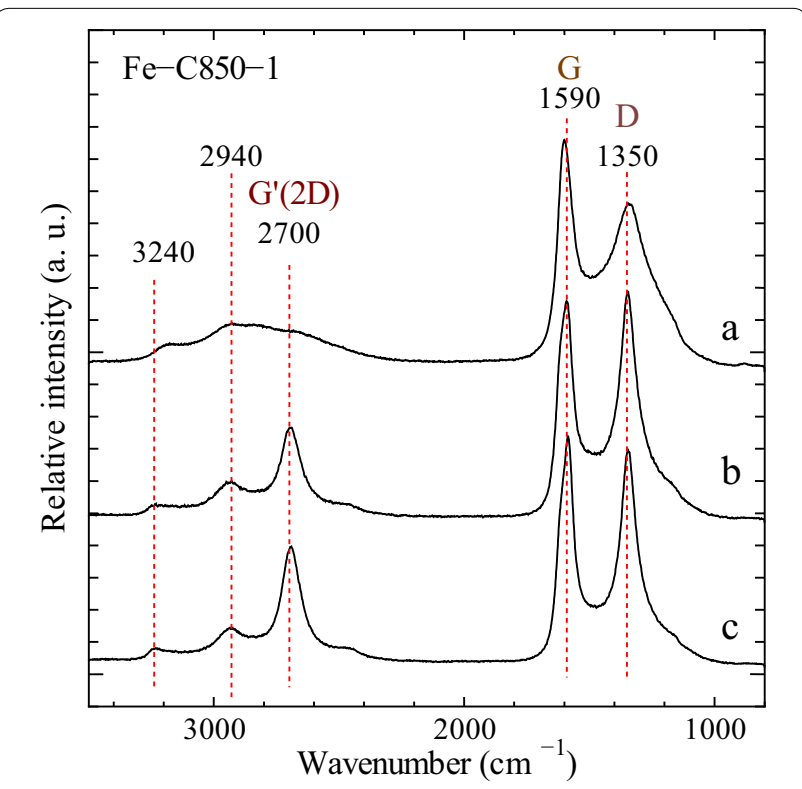

Fig. 2 Measurement-point dependence of Raman spectral line-shape observed on Fe-C850-1 sample: a, Raman spectrum with little or no G'-band; b and c, Raman spectrum with G'-band 
carbon inhomogeneously. The two other spectra exhibit G'-bands; however, the relative G'-band intensity in the bottom spectrum (Fig. 2c) is stronger than that in the middle spectrum (Fig. 2b). The intensity of G'-band relative to that of the G-band was dependent on the measured point on the Fe-C850-1 sample. The same results were obtained from Raman spectroscopic measurements of $\mathrm{Fe}-\mathrm{C} 900-1$.

Conversely, even though being repeated 30 times, the Raman measurement of Fe-C850-2 did not show any spectral types of Fig. 2a, suggesting that Fe-C850-2 might contain little or no amorphous carbon; graphitization probably progresses in $\mathrm{Fe}-\mathrm{C} 850-2$ more actively and homogeneously than in $\mathrm{Fe}-\mathrm{C} 850-1$ and $\mathrm{Fe}-\mathrm{C} 900-1$. In other words, the two-step procedure would be superior to the one-step procedure in graphitizing carbon in ironloaded charcoal under the conditions set in this study when $\mathrm{CT}$ is set to $850^{\circ} \mathrm{C}$.

Moreover, the significant differences in Raman line-shape depending on measurement positions on Fe-C850-1 and Fe-C900-1 suggest that the rapid development of graphite structure in the iron-loaded charcoal might not be observed between 800 and $850{ }^{\circ} \mathrm{C}$ under different carbonization conditions containing the preparation of iron-impregnated wood powder. Further Raman studies on carbonization of iron-impregnated wood under different conditions are required to obtain more detail information about the formation of graphite structures.

\section{Mössbauer spectroscopy}

Figure 3 depicts the ${ }^{57} \mathrm{Fe}$-Mössbauer spectra of the iron-loaded charcoal samples. The resultant Mössbauer parameters and so on are summarized in Table 1. As shown in the figure and the table, the following four iron-species were deconvoluted in the present system: high-spin $\mathrm{Fe}^{3+}$ species, $\mathrm{Fe}_{3} \mathrm{C}, \gamma$-Fe, and $\alpha-\mathrm{Fe}$, highlighted by brown, blue, orange, and green, respectively. $\mathrm{Fe}_{3} \mathrm{C}$ is an iron carbide, and $\gamma$ - $\mathrm{Fe}$ and $\alpha-\mathrm{Fe}$ are metallic iron. The room temperature IS values of iron in the carbide are in the range of $0.17-0.19 \mathrm{~mm} / \mathrm{s}$, and the values agree closely with those reported previously [11-13].

IS value is an important Mössbauer parameter and depends strongly on the oxidation state of iron. In this study, it is assumed that the oxidation number of $\mathrm{Fe}$ in $\mathrm{Fe}_{3} \mathrm{C}$ is zero; in other words, the carbide is assigned to $\mathrm{Fe}^{0}$ species, because the IS values of $\mathrm{Fe}^{0}$ species range from -0.25 to $0.63 \mathrm{~mm} / \mathrm{s}$ according to Ref. [14]. The CTdependence of the relative yields for the four species are illustrated in Fig. 4, where plot symbols of circles and triangles set for the one-step and two-step carbonization

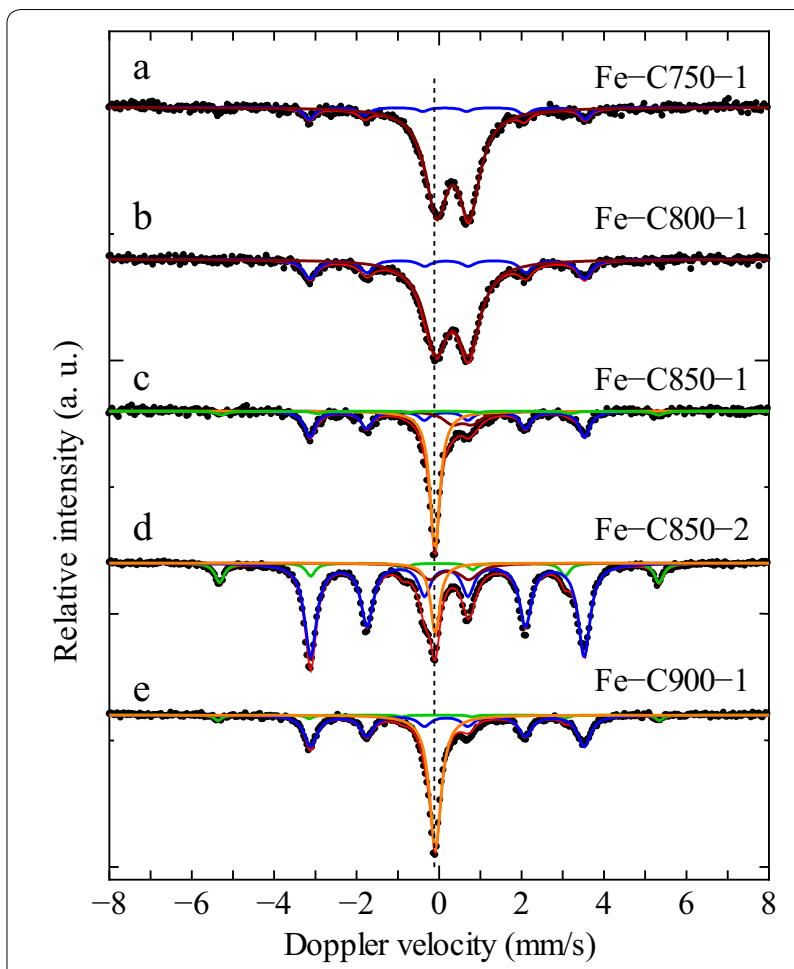

Fig. 3 Mössbauer spectra at $298 \mathrm{~K}$ of iron-loaded charcoal samples: a Fe-C750-1; b Fe-C800-1; c Fe-C850-1; d Fe-C850-2; e Fe-C900-1; Brown solid curve (Doublet): high-spin Fe ${ }^{3+}$ species, Blue solid curve (Sextet 1): $\mathrm{Fe}_{3} \mathrm{C}$, Green solid curve (Sextet 2): a-Fe, Orange solid curve (Singlet): $\gamma-\mathrm{Fe}$, Red solid curve (Overall spectral line), Vertical black dotted line: IS of $\gamma$-Fe

procedures, respectively, and the colors of the symbol for the respective iron-species.

\section{Iron-loaded charcoal synthesized by one-step carbonization}

In the Mössbauer spectra of the iron-loaded charcoal samples carbonized at $750{ }^{\circ} \mathrm{C}$ and $800{ }^{\circ} \mathrm{C}$, two iron species were observed; a doublet absorption due to paramagnetic high-spin $\mathrm{Fe}^{3+}$ species and a sextet due to $\mathrm{Fe}_{3} \mathrm{C}$. The absorption lines attributed to $\alpha$-Fe (sextet) and $\gamma$-Fe (singlet) additionally appear in the Mössbauer spectra of $\mathrm{Fe}-\mathrm{C} 850-1$ and Fe-C900-1. As can be seen both in Figs. 3 and 4 , there are a huge decrease in the $\mathrm{Fe}^{3+}$ species and the corresponding increases in the reduced iron species $\left(\mathrm{Fe}_{3} \mathrm{C}, \alpha\right.$ - $\mathrm{Fe}$, and $\gamma$-Fe) with the rise of CT from 800 to $850{ }^{\circ} \mathrm{C}$, suggesting that the graphitization of carbon is closely related to the generation of metallic iron and/or $\mathrm{Fe}_{3} \mathrm{C}$ in the iron-loaded charcoal. The $\mathrm{Fe}^{3+}$ species disappears completely at $900{ }^{\circ} \mathrm{C}$. These findings should presume that some reductive chemical reactions related to iron progress successively over the wide $\mathrm{CT}$ region. 
Table 1 Mössbauer parameters at $298 \mathrm{~K}$ of iron-loaded charcoal samples

\begin{tabular}{|c|c|c|c|c|c|c|c|}
\hline Sample & Type of split & IS (mm/s) & $\mathrm{QS}(\mathrm{mm} / \mathrm{s})$ & $H(\mathrm{~T})$ & $\mathrm{LW}(\mathrm{mm} / \mathrm{s})$ & Yield* (\%) & Iron species \\
\hline \multirow[t]{2}{*}{ Fe-C750-1 } & Doublet & $0.337(3)$ & $0.792(4)$ & - & $0.64(1)$ & $89(1)$ & High-spin $\mathrm{Fe}^{3+}$ species \\
\hline & Sextet & $0.17(1)$ & $0.07(2)$ & $20.80(8)$ & $0.31(3)$ & $11(1)$ & $\mathrm{Fe}_{3} \mathrm{C}$ \\
\hline \multirow[t]{2}{*}{ Fe-C800-1 } & Doublet & $0.322(3)$ & $0.798(5)$ & - & $0.69(1)$ & $79(1)$ & High-spin $\mathrm{Fe}^{3+}$ species \\
\hline & Sextet & $0.19(1)$ & $0.02(1)$ & $20.70(5)$ & $0.39(2)$ & $21(1)$ & $\mathrm{Fe}_{3} \mathrm{C}$ \\
\hline \multirow[t]{4}{*}{ Fe-C850-1 } & Doublet & $0.56(3)$ & $0.48(4)$ & - & $0.53(8)$ & $13(1)$ & High-spin $\mathrm{Fe}^{3+}$ species \\
\hline & Sextet-1 & $0.184(5)$ & $0.030(10)$ & $20.71(3)$ & $0.32(1)$ & $37(1)$ & $\mathrm{Fe}_{3} \mathrm{C}$ \\
\hline & Sextet-2 & $0.07(3)$ & $-0.09(7)$ & $33.0(2)$ & $0.30(10)$ & $5(1)$ & $\mathrm{a}-\mathrm{Fe}$ \\
\hline & Singlet & $-0.100(2)$ & - & - & $0.293(6)$ & $45(1)$ & $y-\mathrm{Fe}$ \\
\hline \multirow[t]{4}{*}{$\mathrm{Fe}-\mathrm{C} 850-2$} & Doublet & $0.25(1)$ & $0.96(2)$ & - & $0.58(2)$ & $9.4(3)$ & High-spin $\mathrm{Fe}^{3+}$ species \\
\hline & Sextet-1 & $0.188(1)$ & $0.028(2)$ & $20.63(1)$ & $0.350(2)$ & $69.2(3)$ & $\mathrm{Fe}_{3} \mathrm{C}$ \\
\hline & Sextet-2 & $-0.012(4)$ & $0.033(8)$ & $33.12(2)$ & $0.27(1)$ & $11.2(3)$ & $a-F e$ \\
\hline & Singlet & $-0.098(6)$ & - & - & $0.271(6)$ & $10.2(2)$ & $y$-Fe \\
\hline \multirow[t]{3}{*}{ Fe-C900-1 } & Sextet-1 & $0.187(2)$ & $0.034(5)$ & $20.62(2)$ & $0.378(6)$ & $48.3(3)$ & $\mathrm{Fe}_{3} \mathrm{C}$ \\
\hline & Sextet-2 & $-0.015(4)$ & $0.04(2)$ & $33.27(7)$ & $0.21(1)$ & $4.8(5)$ & $a-F e$ \\
\hline & Singlet & $-0.091(1)$ & - & - & $0.346(3)$ & $46.9(3)$ & $\gamma$-Fe \\
\hline
\end{tabular}

IS, isomer shift; QS, quadrupole splitting; $H$, internal magnetic field; $T$, tesla; $L W$, linewidth

* Yields of iron species were calculated from their Mössbauer absorption areas

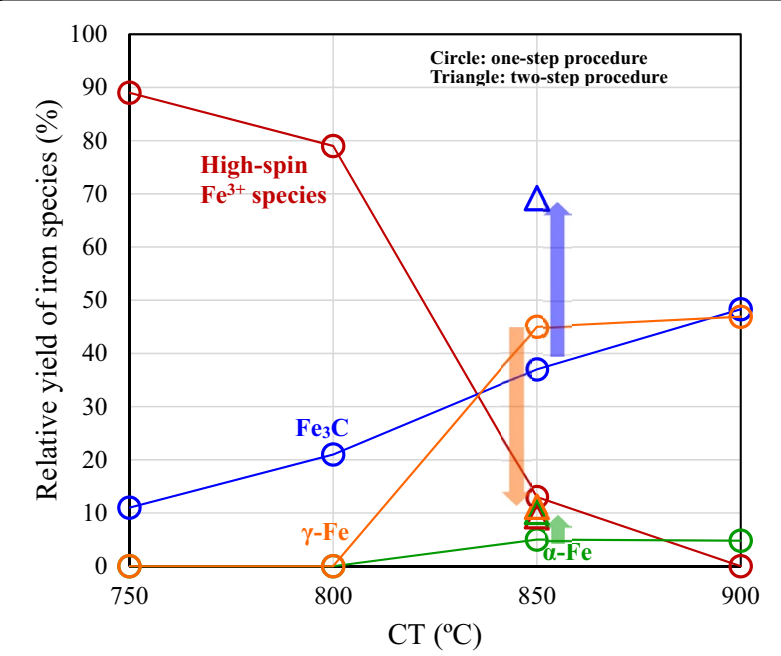

Fig. 4 CT-dependence of iron species yield in charcoal samples. Circle: iron-loaded charcoal synthesized by the one-step procedure, Triangle: iron-loaded charcoal synthesized by a two-step procedure, Brown: high-spin $\mathrm{Fe}^{3+}$, Blue: $\mathrm{Fe}_{3} \mathrm{C}$, Green: $\mathrm{a}-\mathrm{Fe}$, Orange: $\gamma$-Fe

\section{Iron-loaded charcoal synthesized by two-step carbonization}

It is interesting to note that the Mössbauer line-shape of Fe-C850-2 is entirely different from that of Fe-C850-1, which is caused by that the iron-species yields generated at $850{ }^{\circ} \mathrm{C}$ depend on the two carbonization methods: onestep and two-step. Furthermore, precisely comparing the results depicted in Fig. 4, it can be seen that the amount of reduction from $\mathrm{Fe}^{3+}$ to $\mathrm{Fe}^{0}$ species was almost same, however, the reduction products are greatly different; it seems that a substantial part of $\gamma$-Fe detected in the onestep carbonization procedure should transform to $\mathrm{Fe}_{3} \mathrm{C}$ and $\alpha$-Fe in the two-step procedure.

\section{Comprehensive explanation for Mössbauer spectra of iron-loaded charcoal}

With respect to the Mössbauer spectra of Fe-C750-1 and Fe-C800-1, the doublet line shows the IS and quadrupole splitting (QS) value assignable to paramagnetic high-spin $\mathrm{Fe}^{3+}$ species. Although it is difficult to identify a precise chemical species for the paramagnetic $\mathrm{Fe}^{3+}$ specie with a doublet line-shape, it is a key factor for understanding the iron-speciation and reactions in the carbonization process to discuss what are such $\mathrm{Fe}^{3+}$ species in the Mössbauer spectra of Fe-C750-1 and Fe-C800-1. Two possible explanations are proposed for the doublet lines as follows.

(1) The $\mathrm{Fe}^{3+}$ species are iron oxides $\left(\alpha-\mathrm{Fe}_{2} \mathrm{O}_{3}\right.$ and/or $\left.\gamma-\mathrm{Fe}_{2} \mathrm{O}_{3}\right)$; however, superparamagnetic relaxation [15] appears owing to the nano-sized oxide particles.

(2) The $\mathrm{Fe}^{3+}$ ions form Werner-type multinuclear complexes.

The second explanation is probably not appropriate for the iron-loaded charcoal in this study, because $\mathrm{Fe}\left(\mathrm{NO}_{3}\right)_{3}$ hydrates will decompose completely and changed to $\mathrm{Fe}_{2} \mathrm{O}_{3}$ up to $400{ }^{\circ} \mathrm{C}[16,17]$. Moreover, charcoal carbonized at temperatures exceeding $650{ }^{\circ} \mathrm{C}$ would contain neither $\mathrm{H}_{2} \mathrm{O}$ molecules nor hydroxy groups, and almost 
all the functional groups originated from wood constituents were thermally decomposed before the carbonization temperature was reached $[18,19]$. Consequently, the superparamagnetic relaxation effect seems to provide a powerful explanation for the doublet lines.

The IS vales of the doublet lines due to $\mathrm{Fe}^{3+}$ species are compatible with those of hematite $\left(\alpha-\mathrm{Fe}_{2} \mathrm{O}_{3}\right)$ and maghemite $\left(\gamma-\mathrm{Fe}_{2} \mathrm{O}_{3}\right)$ reported previously [20, 21]. The absolute QS values are much larger than that of ordinary hematite or maghemite $[20,21]$, suggesting that the ratio of iron atoms in a sphere with a low electrical symmetry is considerably larger. In other words, the large QS values seem likely to be evidence that a large portion of iron in the particles is present in the surface layers of $\mathrm{Fe}_{2} \mathrm{O}_{3}$ particles because of their nm-scale diameter. For example, if the diameter of $\alpha-\mathrm{Fe}_{2} \mathrm{O}_{3}$ particle is $3 \mathrm{~nm}$, only ten iron atoms are present in this diameter. Hence, the outermost and second surface layers contained approximately $30 \%$ and $20 \%$ of iron atoms, respectively. Similarly, this is applicable to $\gamma-\mathrm{Fe}_{2} \mathrm{O}_{3}$ and, therefore, it is very difficult to distinguish between $\alpha-\mathrm{Fe}_{2} \mathrm{O}_{3}$ and $\gamma-\mathrm{Fe}_{2} \mathrm{O}_{3}$ on the basis of the Mössbauer parameters.

The Mössbauer spectra of Fe-C850-1 and Fe-C900-1 show that almost all $\mathrm{Fe}^{3+}$ ions were reduced to metallic iron and $\mathrm{Fe}_{3} \mathrm{C}$ from 800 to $850{ }^{\circ} \mathrm{C}$. The primary iron species in these charcoal samples are $\gamma$ - $\mathrm{Fe}$ and $\mathrm{Fe}_{3} \mathrm{C}$, and their contents are compatible with each other. Metallic iron in $\alpha$-form is only a minor component at $\sim 5 \%$. The yields of iron species in Fe-C850-2 are significantly different from those of Fe-C850-1, as shown in Fig. 4; it is found that there are a large increase $(32 \%)$ in $\mathrm{Fe}_{3} \mathrm{C}$ and a comparable decrease (35\%) in $\gamma$-Fe. It seems that a large portion of the $\gamma$-Fe component yielded in the one-step procedure might transform to $\mathrm{Fe}_{3} \mathrm{C}$ (major part) and $\alpha$-Fe (minor part) in the two-step process as illustrated by a downward arrow (orange) and upward ones (blue and green) in Fig. 4. This finding is tentatively explainable in terms of the thermodynamic property of $\gamma$-Fe, which is in a metastable phase, forming only in rapidly cooling from a higher temperature than $727^{\circ} \mathrm{C}$, which is the eutectoid transformation temperature [22]; $\gamma$-Fe cannot exist as a thermodynamically stable species below this temperature.

Our possible explanation for the formation of $\mathrm{Fe}_{3} \mathrm{C}$, $\gamma$-Fe, and $\alpha$-Fe during the carbonization of iron-impregnated wood is described as follows. First of all, we postulate an iron-species precursor that could be generated around $500{ }^{\circ} \mathrm{C}$ and transforms directly to $\mathrm{Fe}_{3} \mathrm{C}$ from a higher temperature than $500{ }^{\circ} \mathrm{C}$. Thus, the precursor is abundantly produced during the first stage in the two-step procedure and subsequently changes to $\mathrm{Fe}_{3} \mathrm{C}$ in the second stage. The $\mathrm{Fe}_{3} \mathrm{C}$ portion might not transform into any other iron species. On the other hand, the iron-impregnated wood yields only a small amount of the precursor during the one-step procedure, because the temperature rising rate of $10{ }^{\circ} \mathrm{C} / \mathrm{min}$ is too fast to generate sufficiently the precursor while the reaction media was kept for an hour at $500{ }^{\circ} \mathrm{C}$ in the two-step procedure. Iron other than the precursor might change to $\gamma$-Fe in the temperature range above $727^{\circ} \mathrm{C}$. Most of the metallic iron maintains $\gamma$-form in room temperature by quick cooling; however, a small portion of metallic iron would transform from $\gamma$-form to $\alpha$-form. No observation of metallic iron in Fe-C750-1 and Fe-C800-1 may suggest that the reduction to $\mathrm{Fe}^{0}$ does not sufficiently progress. In other words, the metallic iron may be detected by Mössbauer spectroscopy if charcoal is held at $750{ }^{\circ} \mathrm{C}$ or $800{ }^{\circ} \mathrm{C}$ more than $1.0 \mathrm{~h}$.

\section{Conclusion}

The characterization of iron-loaded charcoal using Mössbauer and Raman spectroscopy provided information on the physicochemical changes in iron and carbon during carbonization, as mentioned below.

The yields of the iron species reduced in the ironloaded charcoal have a positive correlation with the progress of graphitization; moreover, the carbonization conditions (e.g., iron content in wood powder, increasing rate of temperature, retention time at $\mathrm{CT}$, etc.) other than CT should affect the chemical changes of iron and carbon. The two-step carbonization is expected to have an advantage over the one-step carbonization to obtain iron-loaded charcoal applicable to magnetic materials, since the total yield of ferromagnetic iron species, $\mathrm{Fe}_{3} \mathrm{C}$ and $\alpha$ - $\mathrm{Fe}$, in $\mathrm{Fe}-\mathrm{C} 850-2$ is approximately $80 \%$.

A key outcome in this study is the suggestion of a chemical reaction path from $\mathrm{Fe}^{3+}$ species to $\mathrm{Fe}_{3} \mathrm{C}$ not through $\gamma$-Fe in the carbonization of iron-impregnated wood. Further Mössbauer studies on the effects of carbonization conditions are required to elucidate the formation mechanism of reduced iron species.

\section{Abbreviations \\ CT: Carbonization temperature; IS: Isomer shift; QS: Quadrupole splitting; LW: Line width; Fe-C750-1, Fe-C800-1, Fe-C850-1, Fe-C900-1, Fe-C850-2: Fe-C750-1, $\mathrm{FeC} 800-1$, Fe-C850-1, and Fe-C900-1 represent iron-loaded charcoal samples carbonized using the one-step method at $750^{\circ} \mathrm{C}, 800^{\circ} \mathrm{C}, 850^{\circ} \mathrm{C}$, and $900^{\circ} \mathrm{C}$. respectively. Fe-C850-2 represents iron-loaded charcoal sample carbonized at $850^{\circ} \mathrm{C}$ using the two-step method.}

\section{Acknowledgements}

Not applicable.

\section{Authors' contributions}

$T Y, S Y$, and $Y S$ designed this study, and wrote the initial draft of the manuscript. KS and TS prepared the iron-loaded charcoal samples. SY, YK, and TY performed Raman spectroscopic analysis. YS and TT were major contributors in obtaining and analyzing Mössbauer spectra. All authors have contributed to data collection and interpretation, and critically reviewed the manuscript. All authors read and approved the final manuscript. 


\section{Funding}

The authors raised no research funds from external sources for this study.

\section{Availability of data and materials}

Not applicable.

\section{Competing interests}

The authors declare that they have no competing interests.

\section{Author details}

${ }^{1}$ Department of Materials and Life Science, Seikei University, Musashino, Tokyo 180-8633, Japan. ${ }^{2}$ Institute of Wood Technology, Akita Prefectural University, 11-1 Kaieisaka, Noshiro 016-0876, Japan. ${ }^{3}$ Department of Applied and Environmental Chemistry, Kitami Institute of Technology, Kitami, Hokkaido 090-8507, Japan. ${ }^{4}$ Department of Chemistry, Daido University, Takiharu-Cho, Minami-ku, Nagoya 457-8530, Japan.

Received: 19 Auqust 2020 Accepted: 25 November 2020 Published online: 04 December 2020

\section{References}

1. Suzuki K, Suzuki T, Takahashi Y, Okimoto M, Yamada T, Okazaki N, Shimizu Y, Fujiwara M (2005) Preparation of crystallized and mesoporous carbon by nickel-catalyzed carbonization of wood. Chem Lett 34:870-871

2. Suzuki T, Suzuki K, Takahashi Y, Okimoto M, Yamada T, Okazaki N, Shimizu Y, Fujiwara M (2007) Nickel-catalyzed carbonation of wood for coproduction of functional carbon and fluid fuels I: production of crystallized mesoporous carbon. J Wood Sci 53:54-60

3. Suzuki T, Suzuki K, Saito Y, Yasui S, Okazaki N, Yamada T (2008) High electroconductivity of wood char obtained by iron-catalyzed carbonation. Chem Lett 37:798-799

4. Suzuki K, Suzuki T, Takahashi Y, Okimoto M, Yamada T, Okazaki N, Shimizu Y, Fujiwara M (2009) Nickel-catalyzed carbonization of wood for coproduction of functional carbon and fluid fuels 11 : improved fuel quality of oil fraction and increased heating value of gas fraction. J Wood Sci 55:60-68

5. Suzuki T, Shinomoto T, Matsuzaki H, Suzuki K, Okazaki N, Saito Y, Kita H, Tamai H (2011) Production of functional carbon by iron-catalyzed carbonation of biomass-effect of washing with acid followed by atmospheric oxidation on the electroconductivity of crystallized mesoporous wood carbon. Trans Mat Res Soc Jpn 36:417-420

6. Kodama Y, Sato K, Suzuki K, Saito Y, Suzuki T, Konno TJ (2012) Electron microscope study of the formation of graphitic nanostructures in nickelloaded wood char. Carbon 50:3486-3496

7. Suzuki K, Suzuki T, Hattori K, Okazaki N, Saito Y, Kita H, Tamai H (2012) Liquid phase adsorption of dyes and dextrans by crystallized mesoporous wood carbon obtained by nickel-catalyzed carbonization of larch at $900^{\circ} \mathrm{C}$. Wood Carbonization Res 9:21-29
8. Suzuki K, Saito Y, Kita H, Sato K, Konno T, Suzuki T (2017) Production of carbon nanoshell chains by the co-catalyzed carbonization of wood. TANSO No 277:55-62

9. Suzuki K, Saito Y, Okazaki N, Suzuki T (2020) Graphite-shell-chains selectively and efficiently produced from biomass rich in cellulose and chitin. Sci Rep doi:org/. https://doi.org/10.1038/s41598-020-69156-y

10. Pimenta MA, Dresselhaus G, Cançado LG, Jorio A, Saito R (2007) Studying disorder in graphite-based systems by Raman spectroscopy. Phys Chem Chem Phys 9:1276-1294

11. Shinjo T, Itoh F, Takaki H, Nakamura Y, Shikazono N (1964) Fe ${ }^{57}$ Mössbauer effect in $\mathrm{Fe}_{2} \mathrm{~B}$, FeB and $\mathrm{Fe}_{3} \mathrm{C}$. J Phys Soc Jpn 19:1252

12. Prudnikava AL, Fedotova JA, Kasiuk JV, Shulitski BG, Labunov VA (2010) Mössbauer spectroscopy investigation of magnetic nanoparticles incorporated into carbon nanotubes obtained by the injection CVD method. Semiconductor Physics, Quantum Electronics \& Optoelectronics 13:125-131

13. Amagasa S, Nishida N, Kobayashi Y, Yamada Y (2016) Mössbauer study of iron carbide nanoparticles produced by laser in alcohols. Hyperfine Interact 237:110-120

14. Wagner FE, Stievano L (2012) Isomer shifts in solid state chemistry, chap 10. In: Kalvius M, Kienle P (eds) The Rudolf Mössbauer story. SpringerVerlag, Berlin, pp 175-197

15. Nasu S (2013) General introduction to Mössbauer spectroscopy, chap 1. In: Yoshida Y, Langouche G (eds) Mössbauer spectroscopy. SpringerVerlag, Berlin, pp 1-22

16. Gadalla AM, Yu H-F (1990) Thermal decomposition of Fe(III) nitrate and its aerosol. J Mater Res 5:1233-1236

17. Melnikov P, Nascimento VA, Arkhangelsky IV, Zanoni Consolo LZ, De Oliveira LCS (2014) Thermal decomposition mechanism of iron(III) nitrate and characterization of intermediate products by the technique of computerized modeling. J Therm Anal Calorim 115:145-151

18. Yamauchi S (2003) Infrared photoacoustic spectra of Japanese cedar (Cryptomeria japonica D. Don) wood and bark heat-treatment at temperatures ranging from $200^{\circ} \mathrm{C}$ to $1100^{\circ} \mathrm{C}$. Eurasian J For Res $65: 75-78$

19. Yamagishi T, Nishikiori K, Kurimoto Y, Yamauchi S (2019) Cesiumadsorption mechanisms of woody charcoal discussed on the basis of its functional groups and nanostructure. J Wood Sci 65:26-35

20. Murad E, Cashion J (2004) Mössbauer spectroscopy of environmental and their industrial utilization. Kluwer Academic Publishers, Boston

21. Vandenberghe RE, De Grave E (2013) Application of Mössbauer spectroscopy in earth sciences, chap 3. In: Yoshida Y, Langouche G (eds) Mössbauer spectroscopy. Springer-Verlag, Berlin, pp 93-185

22. Benz MG, Elliott JF (1961) The austenite solidus and revised iron-carbon diagram. Trans Met Soc AIME 221:323-331

\section{Publisher's Note}

Springer Nature remains neutral with regard to jurisdictional claims in published maps and institutional affiliations.

\section{Submit your manuscript to a SpringerOpen ${ }^{\circ}$ journal and benefit from:}

- Convenient online submission

- Rigorous peer review

- Open access: articles freely available online

- High visibility within the field

- Retaining the copyright to your article

Submit your next manuscript at springeropen.com 